\title{
Desenvolvimento socioeconômico e Índice de Vulnerabilidade Social (IVS) em São Miguel/RN
}

\author{
Socioeconomic development and Social Vulnerability Index in São Miguel/RN
}

\section{Desarrollo socioeconómico e índice de vulnerabilidad social (SV) en San Miguel/RN}

Thaísa Bruna Costa Nascimentoํhttps://orcid.org/0000-0002-7737-2246

Boanerges de Freitas Barreto Filho² https://orcid.org/0000-0003-1777-3520

\footnotetext{
${ }^{1}$ Universidade do Estado do Rio Grande do Norte - UERN; Pau dos Ferros-RN Brasil , e-mail: thaisa-nascimento@hotmail.com

2 Departamento de Economia da Universidade do Estado do Rio Grande do Norte - UERN; Pau dos Ferros-RN-Brasil, email: boanerges.sms@hotmail.com.
}

Recebido em: 05/12/2020

Aceito para publicação em: 20/03/2021

\section{Resumo}

O trabalho objetiva analisar o desenvolvimento socioeconômico do município de São Miguel/RN, localizado no Alto Oeste Potiguar e seus determinantes de (2000-2010), por meio do Índice de Vulnerabilidade Social (IVS). Utilizou-se pesquisa bibliográfica e levantamento de dados nos sites do Instituto de Pesquisa Econômica Aplicada (IPEA) e do Instituto Brasileiro de Geografia e Estatística (IBGE). O resultado mais expressivo apontou a melhoria das três dimensões e, por consequência, do índice geral, acompanhando o comportamento de outras pesquisas que fizeram uso de indicadores socioeconômicos. Não obstante, tem-se que reconhecer a condição de alta vulnerabilidade social identificada em 2010, sinalizando a necessidade de esforços continuados, especialmente por parte do Poder Público, para superação dos problemas socioeconômicos.

Palavras-chave: Desenvolvimento socioeconômico; Indicadores sociais; Vulnerabilidade social.

\begin{abstract}
Text the work aims to analyze the socioeconomic development of the municipality of São Miguel/RN, located in the Upper West Potiguar and its determinants of (2000-2010), through the Social Vulnerability Index (SV). Bibliographic research and data collection were used on the
\end{abstract}


websites of the Institute of Applied Economic Research (IPEA) and the Brazilian Institute of Geography and Statistics (IBGE). The most expressive result indicated the improvement of the three dimensions and, consequently, of the general index, following the behavior of other studies that used socioeconomic indicators. Nevertheless, it has to be recognized the condition of high social vulnerability identified in 2010, signaling the need for continued efforts, especially by the government, to overcome socioeconomic problems.

Keywords: Socioeconomic development; Social indicators; Social vulnerability.

\section{Resumen}

El trabajo tiene como objetivo analizar el desarrollo socioeconómico del municipio de San Miguel/RN, ubicado en el Alto Oeste de Potiguar y sus determinantes de (2000-2010), a través del índice de vulnerabilidad social (SV). La investigación bibliográfica y la recopilación de datos se utilizaron en los sitios web del Instituto de Investigaciones Económicas Aplicadas (IPEA) y del Instituto Brasileño de Geografía y Estadística (IBGE). El resultado más expresivo indicaba la mejora de las tres dimensiones $\mathrm{y}$, en consecuencia, del índice general, siguiendo el comportamiento de otros estudios que utilizaban indicadores socioeconómicos. Sin embargo, hay que reconocer la condición de alta vulnerabilidad social identificada en 2010, lo que indica la necesidad de que el gobierno continúe esfuerzos, especialmente para superar los problemas socioeconómicos.

Palabras clave: Desarrollo socioeconómico; Indicadores sociales; Vulnerabilidad social.

\section{Introdução}

O desenvolvimento é uma meta perseguida, praticamente, por todas as nações e demais áreas subnacionais, visto que parece inerente ao ser humano buscar o aprimoramento de sua qualidade de vida e, por isso mesmo, cobram providências das autoridades competentes para à implementação de políticas públicas. Como as demais nações, verifica-se que o Brasil persegue, há tempos, o ingresso no seleto grupo com os maiores níveis de desenvolvimento.

Saliente-se que o desenvolvimento é um processo complexo. Segundo Amaro (2003, n.p.), o desenvolvimento é: “Mobilizador de vontades de mudança e de transformação das sociedades e dos indivíduos, tem servido também para avaliar e 
classificar o seu nível de progresso e bem-estar." Em tal processo ${ }^{3}$ é necessário que se tenha conhecimento da realidade, da evolução histórica, da disponibilidade dos fatores e dos distintos usos em que se pode utilizá-los, enfim, da situação concreta e do potencial existente para que se possa alcançar um nível mais elevado. Dada a complexidade na abordagem sobre o desenvolvimento se fez opção pela utilização de indicadores, tendo em vista que são considerados indispensáveis para proporcionarem uma visão abrangente e plural do processo existente nas distintas áreas geográficas.

Os indicadores são importantes para retratar a realidade, sendo que suas interpretações refletem a vida social, econômica, política, cultural, etc., permitindo, dessa forma, direcionar, da melhor maneira possível, o processo do desenvolvimento. $\mathrm{O}$ conhecimento e a utilização que se pode fazer dos indicadores, propiciam uma melhora nos resultados da distribuição dos recursos, pois os referidos índices podem se constituir em instrumentos importantes para a tomada de decisão (JANNUZZI, 2002).

Nesse sentido, ao se identificar as características e aspectos de um município qualquer (território objeto de investigação), a partir de indicadores previamente selecionados, podem ser reveladas as principais questões para a reprodução socioeconômica, que, em última instância, referem-se as variáveis sociais, econômicas e as altercações estruturais do território.

Segundo Camargo (2015), a demonstração dos fatores que induzem ao desenvolvimento socioeconômico, num dado território, contribuem para a identificação das potencialidades e carências que possam representar um desafio para o desenvolvimento e para melhorias na qualidade de vida nas áreas geográficas em que se pretendem alterações estruturais.

Assim, como o processo de desenvolvimento é complexo e multideterminado, faz-se necessário, para efeito analítico, a seleção de elementos que permitam a adequada mensuração das condições existentes. Neste caso, optou-se pela utilização do Índice de

\footnotetext{
3 Sachs (2002) oferece uma leitura sobre o desenvolvimento e as imbricações das distintas dimensões envolvidas no processo. Em Bresser-Pereira (2006) se encontra uma discussão mais economicista do desenvolvimento.
}

Geopauta, Vitória da Conquista ISSN: 2594-5033, V. 5, n. 1, 2021, e7053

Este é um artigo de acesso aberto sob a licença Creative Commons da CC BY 
Vulnerabilidade Social (IVS) criado pelo Instituto de Pesquisa Econômica Aplicada (IPEA).

Acredita-se que a utilização do índice permitiu uma caracterização mais precisa da área de estudo: o município de São Miguel/RN, cuja exposição poderá servir para a realização de intervenções por parte do Poder Público, bem como para a população conhecer a realidade existente e, eventualmente, mobilizar maiores esforços para a promoção de alterações. Neste contexto, a análise focada no município de São Miguel/RN (objeto de estudo), mostra-se interessante, uma vez que permitirá a verificação das condições e determinações do processo do processo de desenvolvimento existente no referido território. Ademais, acredita-se que uma melhor compreensão desse processo pode contribuir no sentido de permitir intervenções e servir como ponto de partida para a discussão de ações que possam ser requeridas pela sociedade micaelense.

Foi formulado o seguinte objetivo geral: analisar o processo de desenvolvimento socioeconômico no município de São Miguel/RN, focando os aspectos sociais e econômicos, a fim de identificar os fatores determinantes e as condições existentes, a partir do IVS (Índice de Vulnerabilidade Social) nos anos 2000/2010. Para a elaboração do trabalho foi utilizada a pesquisa descritiva que, conforme Gil (2010), tem como objetivo a descrição das características de determinada população, melhor compreendendo seus aspectos, condições e relações existentes. Utilizou-se a abordagem quantitativa para exposição e discussão dos dados do IBGE e dimensões e indicadores do IVS, possibilitando a compreensão do fenômeno a partir das relações entre as variáveis. A coleta de dados se deu por meio da exploração dos bancos de dados constantes no IBGE e no IPEA, procedendo-se a elaboração de tabelas e quadros para melhor utilização do IVS correspondentes aos anos 2000 e 2010, para assim retratar a realidade do município de São Miguel/RN e suas vulnerabilidades sociais no referido período. 
Além da introdução, o trabalho foi estruturado em quatro seções. A primeira seção trata do processo de desenvolvimento e os componentes econômico, territorial e social. A seção 2 aborda os indicadores socioeconômicos como instrumentos de mensuração do desenvolvimento e a seção 3 traz os resultados e discussão. Por fim, apresentam as conclusões.

\section{Processo de desenvolvimento e os componentes econômico, territorial e social}

Conforme Bresser-Pereira (2006), o desenvolvimento econômico se torna um fim desejável a partir da constituição de Estados-nação, ou seja, onde um governo controla politicamente um determinado território. O Estado passa a controlar diversos aspectos do processo social, criando novos arranjos institucionais, estabelecendo leis e condutas compatíveis com o funcionamento do mercado, em superação de estruturas organizacionais fundadas na tradição ou religião. $O$ autor ressalta que as ideias modernas associadas a formação dos Estados-nações e a revolução capitalista, descrevendo o desenvolvimento econômico como organização do processo de acumulação de capital com o progresso técnico do trabalho, resultando no aumento do capital, dos salários, padrões de vida, aumento da produtividade e da renda por habitante, portanto, tornando-se um alvo político para os governantes das nações, em função dos benefícios provenientes: poder econômico, militar e melhorias para o conjunto da sociedade.

Os governantes dos distintos países, utilizando-se do aparato do Estado, passaram a conceder incentivos para expansão e consolidação do mercado e, manuseando as diferentes ferramentas existentes, alçaram a promoção do capitalismo, via industrialização, como um pré-requisito para se alcançar o desenvolvimento econômico, assim, lançaram mão de variados expedientes: estimularam o uso dos recursos naturais disponíveis para assegurar a reprodução do capital; induziram o aproveitamento capitalista dos recursos humanos existentes; ofereceram crédito para fomentar os mecanismos de mercado, a pretexto de assegurar a otimização da 
distribuição dos bens e serviços; patrocinaram pesquisas e estudos para ampliar os conhecimentos técnicos e científicos indutores da ampliação do estoque de capital, dentre outras medidas.

Para Vasconcelos e Garcia (1998), o desenvolvimento, em seu percurso, está associado ao crescimento econômico por conter aspectos como alterações na composição do produto e na alocação de recursos pelos diferentes setores da economia. Para além do componente eminentemente quantitativo, observa-se que o desenvolvimento é caracterizado por mudanças qualitativas que impactam no dia a dia das pessoas e nas suas estruturas produtivas, diferente do crescimento que é considerado uma variação quantitativa do produto, mas que, ainda assim, relacionamse, pois, ambos contribuem para melhoria nos padrões e qualidade de vida da população.

Siedenberg (2003) destaca experiências onde ocorreu crescimento econômico sem que existisse o desenvolvimento, ressaltando que a expansão do PIB, por si só, não deve ser considerada um sinônimo do desenvolvimento, contudo chama à atenção para o fato que o crescimento do PIB é fator potencializador para o desenvolvimento, considerando então o crescimento econômico como um elemento necessário, mas não suficiente, para se alcançar melhorias na qualidade de vida.

Na mesma linha, Silva (2013) nota que para existir uma sociedade desenvolvida, deve-se considerar o crescimento da produção, do consumo e da renda, sendo possível aferir o desenvolvimento a partir dos níveis de industrialização e urbanização da sociedade.

Oliveira (2002) considera o conceito de desenvolvimento muito rico, indicando as mudanças de ordem econômica, política e social como requisitos básicos para se alcançar a condição, salienta também a relação do conceito com a ideia de crescimento autossustentado.

Furtado (1968, p. 72) ressalta que “o conceito de desenvolvimento compreende a ideia de crescimento, superando-a". Diz Furtado (2004, apud Veiga 2005, ps. 81-2): 
[...] o crescimento econômico, tal qual o conhecemos, vem se fundando na preservação dos privilégios das elites que satisfazem seu afã de modernização; já o desenvolvimento se caracteriza pelo seu projeto social subjacente. Dispor de recursos para investir está longe de ser condição suficiente para preparar um melhor futuro para a massa da população. Mas quando o projeto social prioriza a efetiva melhoria das condições de vida dessa população, o crescimento se metamorfoseia em desenvolvimento.

Em Furtado fica evidente a ideia da intencionalidade, requerendo esforços, ações e a construção de um consenso que permita e persiga a melhoria do padrão de vida existente. Sem tais premissas, tem-se que o crescimento econômico, por si só, pode não resultar de melhorias nos padrões de vida. Para Sachs (1998, p. 150):

Ao longo dos últimos 50 anos, [a noção de desenvolvimento] se enriqueceu consideravelmente. A ideia simplista de que o crescimento econômico por si só bastaria para assegurar o desenvolvimento foi rapidamente abandonada em proveito de uma caracterização mais complexa do conceito, expressa pelas adições sucessivas de epítetos: econômico, social, cultural, naturalmente político, depois viável [sustainable], enfim, último e recente acréscimo, humano, significando ter como objetivo o desenvolvimento dos homens e das mulheres em lugar da multiplicação das coisas.

Para Dubiel e Raiher ${ }^{4}$ (2013, p. 19), ao analisarem a situação de desenvolvimento dos municípios paranaenses, faz-se necessário “[...] que as variáveis estejam relacionadas entre si e se completem, pois o desenvolvimento é consequência da evolução em conjunto de variáveis econômicas e sociais ao longo do tempo".

Conforme observado nos autores referidos, deve-se considerar o aspecto econômico, pois a produção de excedentes se constitui num dos motores do sistema capitalista, mas é sobejamente notório que a expansão econômica não é suficiente para exprimir o fenômeno do desenvolvimento, requerendo-se uma abordagem pluridimensional para que seja alcançado. Neste sentido, o componente territorial passou a ser considerado nos trabalhos relacionados a temática do desenvolvimento. Para Bresser-Pereira (2008), o desenvolvimento de um território é o processo de

\footnotetext{
${ }^{4}$ As variáveis consideradas no estudo foram: saúde, educação, renda, emprego e produção agropecuária.
} 
acumulação de capital, integração e crescimento do progresso técnico do trabalho e do capital, proporcionando o aumento produtivo, dos salários e do padrão médio de vida da população.

Corrêa (2009) destaca que o estudo do processo de desenvolvimento econômico e a formação de territórios têm como principal finalidade possibilitar a construção de políticas públicas articuladas e promovidas pelo Estado, condizentes, por exemplo, com aquelas que foram adotadas no passado em países europeus, permitindo um conjunto articulado de medidas para assegurar a estruturação dos territórios selecionados e, consequentemente, alçá-los aos níveis desejados de industrialização. O autor enfatiza que foi a partir da década de 1970 que o perfil das políticas adotadas destinadas ao desenvolvimento territorial começou a ganhar destaque. E foi a partir das experiências europeia e norte-americana que a ideia de desenvolvimento de um espaço dependeria, parcialmente, do nível de organização da sociedade em relação aos objetivos que lhes seriam comuns, reconhecendo-se tal aspecto com a expressão da organização territorial existente.

Já a partir da década de 1980, conforme Rodrigues e Santos (2018), a expressão "territorial" ganhou maior ênfase e o desenvolvimento passou a ser correlacionado às dinâmicas regional e local, juntamente com as manifestações culturais, o empreendedorismo, a cooperação, participação e potencialidades existentes nos diferentes territórios. Para além das questões voltadas para o crescimento econômico, a abordagem territorial destaca temas culturais e políticas voltadas para a transformação social, onde a sociedade organizada tem a capacidade de construir parcerias com os diversos agentes presentes no território e/ou agentes externos com capacidade de influenciar o processo, buscando compartilhar o conhecimento sobre a realidade vivida e aquela almejada, bem como estabelecer as necessárias mediações para a construção de políticas públicas promotoras do desenvolvimento territorial. Nesse sentido, o desenvolvimento deixa de ser visto apenas em seu âmbito mais universalista (escala 
nacional) e passa a considerar as diferenciações territoriais, inclusive as características internas das comunidades.

O território pode dispor de características próprias, conter vantagens competitivas individuais que, junto com a colaboração da sociedade, podem permitir o impulsionamento das atividades produtivas e a ampliação das possibilidades para que as populações possam desfrutar melhores condições de vida. Segundo Pires (2016), o desenvolvimento territorial está fundado na forma que a sociedade organiza a produção social ${ }^{5}$ e como ela participa da criação de expectativas, ou seja, na perspectiva do desenvolvimento territorial as localidades e as regiões retornam as fontes típicas de vantagens competitivas e de solidariedade descentralizada a partir da intensificação do processo de globalização. Pires (2016) destaca também o potencial humano dos territórios, permitindo que surjam, aflorem e estimulem novas capacidades, impulsionando possíveis potencialidades. Neste sentido, os impulsos aos atores sociais e aos agentes econômicos devem estar apropriados e assegurados, via políticas públicas, para que exista essa interação.

Rodrigues e Santos (2018), defendem que deve existir uma adequação na formulação e modulação para que as políticas atuem de forma eficiente no território. Tal processo só é possível quando se considera a importância dos agentes existentes no território, isso porque:

A abordagem territorial abrange as escalas dos processos de desenvolvimento e
implica um método para favorecê-lo - reconhecendo não ser resultado de uma
ação verticalizada do poder público - a partir de condições criadas para
mobilizar os agentes locais para atuarem em termos de visão futura, elaborar
diagnóstico de suas potencialidades e limitações (que contemple os próprios
meios para se obter o desenvolvimento sustentável). Assim, a perspectiva
territorial permite formular uma proposta centrada nas pessoas que consideram
a interação dos sistemas socioculturais e ambientais e que contemplam a
integração produtiva e o aproveitamento competitivo de seus recursos como

${ }^{5}$ Diz Barreto Filho (2018, p. 32): “A divisão do trabalho implica em diferenciações espaciais (produção de espaços heterogêneos), embora o processo de acumulação capitalista promova a homogeneização a partir de seu caráter intrinsicamente expansível. Esse movimento homogeneização-heterogeneização indica os diferentes contextos históricos em que operam as forças produtivas, as diferentes dotações de recursos naturais disponíveis, além de fatores extra econômicos, como: a estrutura de poder, as relações sociopolíticas, aspectos culturais etc."

Geopauta, Vitória da Conquista ISSN: 2594-5033, V. 5, n. 1, 2021, e7053

Este é um artigo de acesso aberto sob a licença Creative Commons da CC BY 
meios que possibilitam a cooperação e a corresponsabilidade dos atores sociais pertencentes ao território (PERICO, 2009, apud SILVA, 2013, p. 153).

Faz-se necessária a ação/interação em vários níveis administrativos e hierárquicos para que se estabeleça a descentralização das decisões e melhor atuação dos agentes existentes nos diferentes territórios, isso por que os agentes mobilizados, sentindo-se parte integrante do processo, podem utilizar as potencialidades sociais, econômicas, ambientais etc. e, assim, criar/potenciar as condições para que o processo de desenvolvimento se estabeleça e floresça.

Verifica-se que o desenvolvimento é um processo que encampa distintas dimensões: econômica, territorial, social, ambiental, enfim, um fenômeno complexo e multideterminado. Sendo indispensável apostar na capacidade da espécie humana, apesar dos enormes percalços, de buscar o desenvolvimento como um processo que "passa pela libertação humana com relação à opressão material, o que supõe partilha equitativa dos bens e a supressão de todos os entraves que impedem seu desabrochar, na busca de uma melhor situação" (SACHS, 1998, p. 151). Neste aspecto, o desenvolvimento, considerando a dimensão social do processo, requer a superação dos entraves que bloqueiam as possibilidades para que um contingente substancial da população humana consiga alcançar "uma situação melhor". Parece razoável supor que boa parte das decisões políticas deve compartilhar com tal priorização, contudo, as estratégias que devem ser implementadas para se alcançar um resultado ainda geram muitos debates e controvérsias. Em tal perspectiva fica evidente que o desenvolvimento social:

[...] não se reduz ao alívio imediato da pobreza, ou a uma orientação exclusiva para os grupos socialmente mais vulneráveis, tampouco autoriza que, de maneira simplista, se contraponha o mercado ao Estado e este à sociedade, ou ainda a política econômica à política social. Ao mesmo tempo, não cabe ignorar que o próprio mercado de trabalho pode atuar como elemento estruturador das desigualdades e da exclusão social (LAMPREIA, 1995, p. 18).

A necessária articulação das políticas econômica e social elaboradas e executadas pelo Governo Federal se apresenta como elemento central, entretanto, não se deve 
menosprezar as diferentes situações que caracterizam os recortes subnacionais, mais ainda de um país continental como é o Brasil. Assim, assume grande relevância a coleta de dados e informações acerca dos diferentes territórios para a produção de indicadores, bem como o reconhecimento dos distintos processos históricos que constituem o mosaico da realidade brasileira.

\section{Indicadores socioeconômicos como instrumentos de mensuração do desenvolvimento}

Um indicador social é uma medida, em geral quantitativa, dotada de significado social substantivo, usado para substituir, quantificar ou operacionalizar um conceito social abstrato, de interesse teórico (para a pesquisa acadêmica) ou programático (para a formulação de políticas). É um recurso metodológico, empiricamente referido, que informa algo sobre um aspecto da realidade social ou sobre mudanças que estão se processando numa determinada realidade (JANNUZZI, 2001).

A expansão do uso dos indicadores sociais no Brasil, segundo Jannuzzi (2001), deu-se a partir de fatores, como: o recente aumento democratização política, maior acesso a informação, início de organizações sociais firmes, pressão popular por maior transparência nos gastos públicos e ainda a problemas históricos como pobreza, desigualdade, elevação do desemprego e exclusão social. Ademais, conforme o autor, as divulgações realizadas pela mídia sobre os resultados de pesquisas socioeconômicas contribuíram significativamente para a popularização dos indicadores sociais.

Indicadores possibilitam diagnósticos de caráter social, econômico, do nível de desenvolvimento, sendo compreendidos a partir das mudanças socioeconômicas processadas num determinado local, ou região, ou país (JANNUZZI, 2001).

Na visão de Siedenberg (2003, p. 68) os "indicadores de desenvolvimento socioeconômico nada mais são do que medidas estatísticas representativas de um recorte da realidade que têm sentido somente quando se inserem num contexto teóricometodológico que lhe empresta o respectivo significado". Os indicadores 
socioeconômicos possibilitam dimensionar o desenvolvimento e evidenciar seus elementos sociais.

A partir do uso de indicadores sociais se observa uma dada realidade, permitindo comparações, verificando-se, por exemplo, os impactos provenientes da execução de alguma política pública, de forma informativa, avaliativa, normativa e decisória, contribuindo para um melhor direcionamento e implementação de objetivos, metas e estratégias de políticas, contribuindo para aumentar os mecanismos de controle social. Para Jannuzzi (2001, p. 33):

\begin{abstract}
Os indicadores sociais são insumos básicos e indispensáveis em todas as fases do processo de formulação e implementação das políticas públicas sejam elas programas e qualificação da mão de obra, projetos e expansão da infraestrutura urbana ou ações localizadas de distribuição de alimentos ou garantia de renda mínima.
\end{abstract}

Os indicadores sociais, se utilizados de forma responsável e coerente, possibilitam avaliação das condições de vida da população de um país ou de um território subnacional. Jannuzzi (2001) ressalta sua eficiência para o monitoramento das condições de vida e bem-estar social, pelo Poder Público, para a devida identificação de situações de risco social e redução das desigualdades sociais.

Para o IPEA (2009), os indicadores sociais se tornaram necessários para o direcionamento de políticas públicas destinadas ao equacionamento de problemas relacionados a desigualdade social. com tal propósito o IPEA desenvolveu o IVS.

O IVS é um indicador que conquistou grande destaque, pois em suas publicações apresentam diferentes e possíveis situações de exclusão e vulnerabilidade social, indicando aspectos, para além do componente monetário (Renda), como desemprego, dificuldades de inserção social, doenças e violência etc. Diante disso:

O IVS é um índice sintético que reúne indicadores do bloco de vulnerabilidade social do ADH [Atlas do Desenvolvimento Humano], os quais, apresentados por meio de cartogramas e estruturados em diferentes dimensões, servem de suporte para a identificação de porções do território onde há a sobreposição daquelas situações indicativas de exclusão e vulnerabilidade social no território, de modo a orientar gestores públicos municipais, estaduais e federais para o

Geopauta, Vitória da Conquista ISSN: 2594-5033, V. 5, n. 1, 2021, e7053 
desenho de políticas públicas mais sintonizadas com as carências e necessidades presentes nesses territórios (IPEA, 2009, p. 12).

O IVS é constituído por diferentes indicadores sociais, que possibilitam a identificação de situações sociais, apontando elementos para além da pobreza, ou seja, não identificam apenas a insuficiência de recursos monetários (FUNDAÇÃO CEPRO, 2018). Sabe-se que os impactos sociais e econômicos afetam de diferentes formas cada setor ou região, que podem ter mais relevância em determinados espaços que estão mais propensos a serem mais ou menos vulneráveis a determinados acontecimentos. Segundo o IPEA (2009), o IVS é composto por três dimensões: a Infraestrutura Urbana, Capital Humano e Renda e Trabalho, proporcionando e facilitando um mapeamento singular da exclusão e da vulnerabilidade social para os municípios brasileiros.

O IPEA (2009) estabeleceu as três dimensões do IVS, como:

1) O Capital Humano é referente aos ativos e estruturas que determina as perspectivas do presente e futuras de inclusão social dos indivíduos, fundamentadas em saúde e educação, já que não retratam apenas se existe, atualmente ou não, determinados recursos, mas também demonstra se as gerações mais recentes têm potencial de possuilos; 2) O de Renda e Trabalho é composto dos indicadores relativos à insuficiência de renda presente e também fatores relacionados ao fluxo de renda, insegurança de renda, desocupação de adultos, ocupação informal de adultos pouco escolarizados, dependência com relação à renda de pessoas idosas, assim como a presença de trabalho infantil e; por último, 3) a Infraestrutura Urbana, que engloba as situações de acessibilidade aos serviços de saneamento básico e de mobilidade urbana. Sendo que a junção dos três sub índices apontam aspectos que impactam significativamente o bemestar das pessoas (IPEA, 2009).

Segundo o IPEA (2009, p. 19): “O IVS é o resultado da média aritmética dos sub índices: IVS Infraestrutura Urbana, IVS Capital Humano e IVS Renda e Trabalho, cada um deles entra no cálculo do IVS final com o mesmo peso." A Fundação CEPRO (2018) ressalta que, para a construção do IVS e de suas dimensões, são necessárias a composição de pesos equivalentes para cada uma delas, empregando parâmetros 
máximos e mínimos e, assim, transformando-os em um indicador padronizado, variando de 0,000 a 1,000. "Cada indicador teve seu valor normalizado numa escala que varia entre 0 a 1 , em que 0 corresponde à situação ideal, ou desejável, e 1 corresponde à pior situação" (CEPRO, 2018, p. 12).

O gráfico 1 apresenta as faixas de distribuição do IVS, indicando os seus respectivos pesos para cada situação de vulnerabilidade.

Gráfico 1 - Faixas do Índice de Vulnerabilidade Social

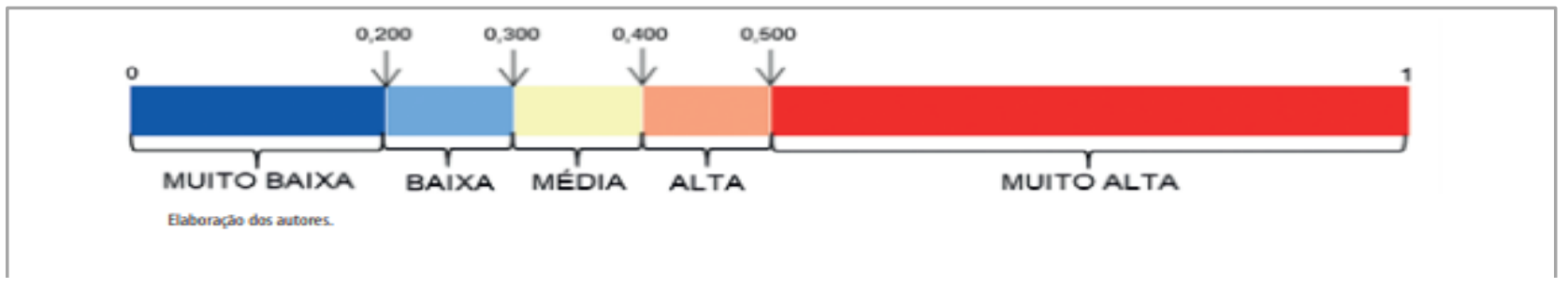

Fonte: IPEA (2015) apud CEPRO (2018).

O Quadro 1 reúne os indicadores que compõem as dimensões do IVS, apontando os valores em cada um dos anos analisados referentes ao Brasil.

Quadro 1 - Índice de Vulnerabilidade Social do Brasil 2000/2010

\begin{tabular}{|c|c|c|c|}
\hline \multicolumn{2}{|r|}{ Brasil } & 2000 & 2010 \\
\hline \multicolumn{2}{|r|}{ IVS } & 0,446 & 0,326 \\
\hline $\begin{array}{c}\text { IVS } \\
\text { Infraestrutura } \\
\text { Urbana }\end{array}$ & $\begin{array}{l}\text { IVS Infraestrutura Urbana } \\
\text { a) \% pessoas em domicílios com abastecimento de água e } \\
\text { esgotamento sanitário adequados } \\
\text { b) \% da população que vive em domicílios urbanos sem } \\
\text { serviço de coleta de lixo } \\
\text { c) \% de pessoas que vivem em domicílios com renda per } \\
\text { capita inferior meio salário mínimo e que gastam mais de } \\
\text { uma hora até o trabalho no total de pessoas ocupadas, } \\
\text { vulneráveis e que retornam diariamente do trabalho }\end{array}$ & $\begin{array}{c}0,351 \\
\text { a) } 8,91 \\
\text { b) } 8,88\end{array}$ & $\begin{array}{c}0,295 \\
\text { a) } 6,12 \\
\text { b) } 2,98\end{array}$ \\
\hline $\begin{array}{c}\text { IVS Capital } \\
\text { Humano }\end{array}$ & $\begin{array}{l}\text { IVS Capital Humano } \\
\text { a) Mortalidade até } 1 \text { ano de idade } \\
\text { b) \% de crianças de } 0 \text { a } 5 \text { anos que não frequentam a escola } \\
\text { c) \% de pessoas de } 6 \text { a } 14 \text { anos que não frequentam a escola } \\
\text { d) \% de mulheres de } 10 \text { a } 17 \text { anos de idade que tiveram } \\
\text { filhos } \\
\text { e) \% de mães chefes de família, sem fundamental completo } \\
\text { e com pelo menos um filho menor de } 15 \text { anos, no total de } \\
\text { mães chefes de família } \\
\text { f) taxa de analfabetismo da população de } 15 \text { anos ou mais } \\
\text { de idade } \\
\text { g) \% de crianças que vivem em domicílios em que nenhum } \\
\text { dos moradores tem o ensino fundamental completo }\end{array}$ & $\begin{array}{l}\text { 0,503 } \\
\text { a) } 30,57 \\
\text { b) } 76,21 \\
\text { c) } 6,89 \\
\text { d) } 3,51\end{array}$ & $\begin{array}{c}\text { 0,362 } \\
\text { a) } 16,7 \\
\text { b) } 56,85 \\
\text { c) } 3,31 \\
\text { d) } 2,89\end{array}$ \\
\hline
\end{tabular}

Geopauta, Vitória da Conquista ISSN: 2594-5033, V. 5, n. 1, 2021, e7053

Este é um artigo de acesso aberto sob a licença Creative Commons da CC BY 
NASCIMENTO, T.B.C.; FILHO, B. de F.B.

\begin{tabular}{|c|c|c|c|}
\hline & $\begin{array}{l}\text { h) \% de pessoas de } 15 \text { a } 24 \text { anos que não estudam, não } \\
\text { trabalham e possuem renda familiar per capita igual ou } \\
\text { inferior a meio salário mínimo (2010) na população total } \\
\text { dessa faixa etária }\end{array}$ & g) 48,86 & g) 30,39 \\
\hline $\begin{array}{l}\text { IVS Renda e } \\
\text { Trabalho }\end{array}$ & $\begin{array}{l}\text { IVS Renda e Trabalho } \\
\text { a) Proporção de pessoas com renda domiciliar per capita } \\
\text { igual ou inferior a meio salário mínimo (2010) } \\
\text { b) Taxa de desocupação da população de } 18 \text { anos ou mais } \\
\text { de idade } \\
\text { c) \% de pessoas de } 18 \text { anos ou mais de idade sem } \\
\text { fundamental completo e em ocupação informal } \\
\text { d) \% de pessoas em domicílios com renda per capita igual } \\
\text { ou inferior a meio salário mínimo ( } 2010 \text { ) e dependentes de } \\
\text { idosos } \\
\text { e) Taxa de atividade das pessoas de } 10 \text { a } 14 \text { anos de idade }\end{array}$ & $\begin{array}{l}\text { b) } 13,82 \\
\text { c) } 48,71 \\
\text { d) } 3,41 \\
\text { e) } 9,28\end{array}$ & $\begin{array}{l}\text { b) } 7,29 \\
\text { c) } 35,24 \\
\text { d) } 2,42\end{array}$ \\
\hline
\end{tabular}

Fonte: IPEA (2015) apud CEPRO (2018).

O Quadro 1 mostra que o Brasil, de 2000 a 2010, obteve uma melhoria no IVS de 26,90\%, deslocando a faixa de alta para média vulnerabilidade social. A dimensão que mais contribuiu para essa movimentação foi a dimensão Renda e Trabalho, que contabilizou uma melhora de 34,02\%. Em seguida, a dimensão Capital Humano que melhorou 28,03\%. Por fim, tem-se a dimensão Infraestrutura Urbana que teve uma evolução de $15,95 \%$. Os resultados sugerem que o país demonstrou maior atenção para as políticas de emprego e renda, assim como buscou a melhoria da qualidade da força de trabalho.

O retrato nacional, a partir do IVS, evidenciou os avanços provenientes da expansão econômica, com a geração de emprego e renda, bem como capturou as melhorias decorrentes da expansão e implantação de novas políticas públicas, destacando-se a valorização real do salário mínimo e maiores inversões públicas em saúde, educação e assistência social.

Conforme salientado a utilização dos indicadores sociais se faz necessária para a elaboração, implementação, avaliação e eventuais calibrações de políticas públicas. Ademais, de acordo com o IPEA (2009), a existência de desenvolvimento humano, juntamente com a melhoria dos indicadores da vulnerabilidade social, resulta em 
prosperidade social, que é o acontecimento simultâneo do alto desenvolvimento humano com a baixa vulnerabilidade social.

Observa-se que a ocorrência (ou não) de vulnerabilidade social em determinada área geográfica se constitui em importante balizador para as intervenções do Estado e para aferição se as medidas adotadas estão surtidos os efeitos esperados e/ou demandam ajustes. Neste sentido, observando-se a realidade do país e de diferentes recortes geográficos subnacionais, verifica-se que, ao longo da primeira década do século XXI, um aspecto comum aos trabalhos que utilizaram o IVS foi que:

\footnotetext{
De maneira geral e sintética, todas as localidades analisadas [...], sejam elas Unidades da Federação (UFs), RMs [Regiões Metropolitanas], municípios ou Unidades de Desenvolvimento Humano (UDHs), apresentaram redução da vulnerabilidade social entre os anos de 2000 e 2010 (COSTA, MARGUTI, PIRANI, 2016, p. 14).
}

Pelo exposto, percebe-se que o IVS tem servido para a elaboração de trabalhos em virtude de sua funcionalidade e adequação para a realização de investigações mais abrangentes sobre a pobreza, indo além da questão eminentemente econômica (Renda) e buscando abarcar um conjunto mais representativo de dados e, podendo ser utilizado para diferentes escalas territoriais.

\section{Resultados e discussão}

São Miguel $^{6}$ é um município brasileiro localizado no estado do Rio Grande do Norte (Figura 2), que, segundo o IBGE (2010), possui uma área territorial de 166,233 $\mathrm{km}^{2}$, situado na região do Alto Oeste Potiguar, a uma distância de 433,6 até a capital do estado, Natal. Limita-se com os municípios de Doutor Severiano ao norte; Venha-Ver ao sul; Coronel João Pessoa e Encanto a leste e Icó/CE e Pereiro/CE a oeste.

\footnotetext{
${ }^{6}$ A origem do município ocorreu com a chegada do português Manoel José de Carvalho, responsável pela formação do povoado no entorno de uma lagoa, no dia 29 de setembro de 1750, data religiosa de São Miguel Arcanjo, que se tornou, então, padroeiro local. Em 9 de setembro de 1875 São Miguel passou a condição de Vila, e em 11 de dezembro de 1876, a Vila foi desmembrada de Pau dos Ferros, tornando-se emancipada (IBGE, 2017).
}

Geopauta, Vitória da Conquista ISSN: 2594-5033, V. 5, n. 1, 2021, e7053

Este é um artigo de acesso aberto sob a licença Creative Commons da CC BY 
Mapa 1 - Localização Geográfica do município de São Miguel/RN

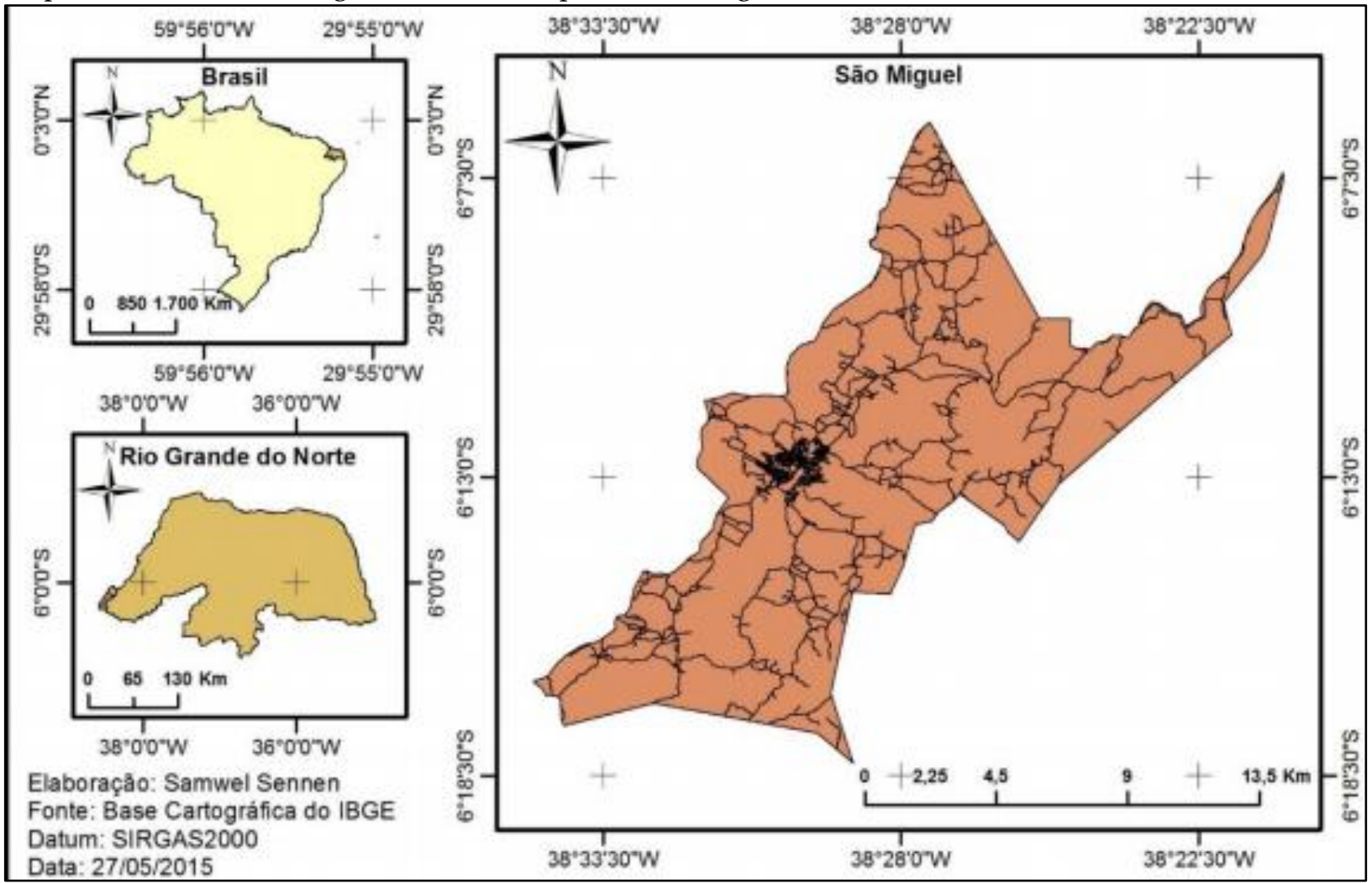

Fonte: Silva e Bezerra (2018, p. 131).

A população do município em 2010, segundo o IBGE (2010), era de 22.157 habitantes, estando em $25^{\circ}$ lugar como município mais populoso do Rio Grande do Norte, apresentando uma densidade populacional de 129,05 hab/km². Com 6.197 domicílios particulares permanentes, onde $4.166(67,20 \%)$ habitantes viviam na zona urbana e 2.031 na zona rural (32,77\%), sendo que 11.585 habitantes eram do sexo feminino (52,29\%) e 10.572 do sexo masculino $(47,71 \%)$.

Ainda de acordo com IBGE (2000 e 2010), sobre as condições de saneamento básico que incluem uma série de serviços fundamentais para a qualidade de vida de uma população, verificou-se que, em 2000, a oferta de saneamento dentro das expectativas adequadas foram de modestíssimos 0,3\%, com oferta inadequada se observou 33,3\% e semi-adequados 66,4\%. Já em 2010 os serviços adequados eram 2,4\%, inadequados 8,7\% e semi-adequados 88,9\%. Percebendo-se uma melhoria nas condições dos serviços de saneamento básico ofertados a população local, mas ainda insuficientes, uma vez que o percentual de oferta adequada do serviço ainda era muita baixa. 

NASCIMENTO, T.B.C.; FILHO, B. de F.B.

O Produto Interno Bruto (PIB) a preços correntes do município de São Miguel/RN, em 2017, foi de R\$218.339.290,00, com PIB per capita de R\$9.247,75, sendo que o percentual das receitas oriundas de fontes externas, em 2015, correspondeu a 82,4\%, com Índice de Desenvolvimento Humano Municipal (IDHM), em 2010, de 0,606, e, em 2017, o salário médio formal mensal era de 2,0 salários mínimos (IBGE, 2017).

Sobre a estrutura de ocupação da população micaelenses, a parcela da população com idade igual ou superior a dezoito anos era de 52,2\%, sendo economicamente ativa e ocupada, os indivíduos que se encontravam fora da idade de trabalho oficial era de $40,6 \%$ e para os que estavam desocupados se observou um percentual de 7,2\% (IBGE, 2010). Em linhas gerais, percebe-se que o ambiente econômico, acompanhando a conjuntura nacional, melhorou no período, mas ainda apresentando circunstâncias preocupantes, como a elevada dependência de receitas externas e o elevado percentual da população com rendimentos muito baixos.

A Tabela 1 apresenta os dados do IVS para os municípios integrantes da Microrregião da Serra de São Miguel, para o período compreendido de 2000 e 2010. Conforme mencionado, o IVS apresenta como situação ideal a inexistência de vulnerabilidade (índice igual a zero) para o índice geral e para cada uma das dimensões. De outro lado, quanto mais próximo de 1, tem-se que pior é a condição existente, com o índice igual a 1 indicando a maior vulnerabilidade.

Tabela 1 - Índice de Vulnerabilidade Social na Microrregião da Serra de São Miguel de 2000 a 2010

\begin{tabular}{l|l|l|c}
\hline \multicolumn{1}{c|}{ Municípios } & Ano & IVS & Variações 2000/2010 \\
\hline Coronel João Pessoa & 2000 & 0.554 & $-26,71 \%$ \\
\hline Doutor Severiano & 2010 & 0.406 & $-21,78 \%$ \\
\hline & 2000 & 0.528 & \\
\hline Encanto & 2010 & 0.413 & $-30,88 \%$ \\
\hline Luís Gomes & 2000 & 0.586 & $-17,87 \%$ \\
\hline & 2010 & 0.405 & \\
\hline Major Sales & 2000 & 0.554 & $-20 \%$ \\
\hline & 2010 & 0.455 & \\
\hline Riacho de Santana & 2000 & 0.482 & $-21,91 \%$ \\
\hline
\end{tabular}

Geopauta, Vitória da Conquista ISSN: 2594-5033, V. 5, n. 1, 2021, e7053

Este é um artigo de acesso aberto sob a licença Creative Commons da CC BY 


\begin{tabular}{l|c|c|c}
\hline São Miguel & 2000 & 0.624 & $-29,96 \%$ \\
\hline & 2010 & 0.437 & $-19,87 \%$ \\
\hline Venha-Ver & 2000 & 0.644 & \\
\hline & 2010 & 0.516 & $-29,8 \%$ \\
\hline Água Nova & 2000 & 0.59 & 0.414 \\
\hline
\end{tabular}

Fonte: IPEA (2000, 2010).

Em 2000, o município de São Miguel/RN apresentou um índice total do IVS de 0.624, enquadrando-se como um município de muita alta vulnerabilidade social. Em 2010, observa-se uma diminuição do índice de vulnerabilidade social passando-se a enquadrar na faixa de alta vulnerabilidade social, com um índice de 0.437 e representando uma melhoria equivalente a uma redução de 29,9\% do IVS nos anos de 2000 e 2010.

O município de Doutor Severiano/RN, para o período, reduziu o índice em 21,78\%, enquanto que Luís Gomes/RN reduziu em 17,87\%, Major Sales/RN menos 20\%, Venha-Ver/RN menos 19,87\%, Água Nova/RN menos 29,8\%, Coronel João Pessoa/RN menos 26,71\% e Riacho de Santana/RN menos 21,91\%. Dessa forma, na Microrregião da Serra de São Miguel, o município de São Miguel/RN só perdeu para o município de Encanto/RN que obteve o melhor desempenho microrregional para o referido período, com redução no IVS de 30,88\%.

Dadas as características do IVS, reconhece-se sua limitação para comparação entre municípios com características e processos históricos e produtivos também diferenciados, mas é merecedor de atenção que o polo microrregional, São Miguel/RN, tivesse o segundo pior IVS em 2000 (melhor apenas do que Venha-Ver/RN), e, em 2010, permanecesse em antepenúltimo (melhor que Venha-Ver/RN e Luís Gomes/RN). Destacando-se que, ao menos no período, a condição de polo regional não se traduziu em melhorias nos indicadores sociais do município.

A Tabela 2 descreve a evolução do IVS - Dimensão Renda e Trabalho do município de São Miguel/RN (2000-2010). 
Tabela 2 - Índice de Vulnerabilidade Social: Dimensão Renda e Trabalho do município de São Miguel/RN (2000-2010)

\begin{tabular}{|c|c|c|c|}
\hline & \multicolumn{2}{|c|}{ ANO } & Variação 2000- \\
\hline & 2000 & 2010 & - \\
\hline IVS Dimensão Renda e Trabalho & 0.817 & 0.585 & $-28,39 \%$ \\
\hline $\begin{array}{l}\text { Proporção de pessoas com renda domiciliar per capita igual ou } \\
\text { inferior a meio salário mínimo (salário de referência de 2010) }\end{array}$ & 84,16 & 65,14 & $-22,59 \%$ \\
\hline Taxa de desocupação da população de 18 anos ou mais de idade & 9,83 & 7,19 & $-26,85 \%$ \\
\hline $\begin{array}{l}\text { \% de pessoas de } 18 \text { anos ou mais sem fundamental completo e em } \\
\text { ocupação informal }\end{array}$ & 80,72 & 64,56 & $-20 \%$ \\
\hline $\begin{array}{l}\text { \% de pessoas em domicílios com renda per capita inferior a meio } \\
\text { salário mínimo (salário de referência de 2010) e dependentes de } \\
\text { idosos }\end{array}$ & 10,38 & 5,59 & $-46,14 \%$ \\
\hline Taxa de atividade das pessoas de 10 a 14 anos de idade & 24,56 & 18,92 & $-22.96 \%$ \\
\hline
\end{tabular}

Fonte: IPEA (2000, 2010).

Em relação a dimensão Renda e Trabalho do IVS, que abrange os indicadores de insegurança, renda e precariedade nas relações de trabalho, verifica-se que São Miguel/RN obteve um indicador de 0.817, que reduziu para 0.585 em 2010, ou seja, a melhora na dimensão foi de $28,39 \%$, tal desempenho não alterou a posição na faixa de vulnerabilidade social na qual o município se encontrava, apesar da redução do índice, o município permaneceu em situação de muito alta vulnerabilidade social na dimensão Renda e Trabalho do IVS.

Conforme Tabela 2, o percentual de pessoas com renda domiciliar per capita igual ou inferior a $\mathrm{R} \$ 255,00$ (duzentos e cinquenta e cinco reais), em 2000 era de 84,16\%; a população economicamente ativa desocupada com 18 anos ou mais de idade era de 9,83\%; o percentual de pessoas de 18 anos ou mais sem fundamental completo e em ocupação informal correspondeu a 80,72\%; as pessoas em domicílios com renda per capita inferior a meio salário mínimo e dependentes de idosos foi de $10,38 \%$ e a taxa de atividade das pessoas de 10 a 14 anos de idade foi de $24,56 \%$.

Para o ano de 2010, o município obteve uma melhoria nos índices para todos os indicadores, alguns mais que outros, para as pessoas com renda domiciliar per capita igual ou inferior a $\mathrm{R} \$ 255,00$ (duzentos e cinquenta e cinco reais), a proporção de 
pessoas diminuiu 22,59\%; a taxa de desocupação da população de 18 anos ou mais de idade caiu $26,85 \%$, esse indicador engloba todos aqueles que procuram emprego e não obtiveram êxito. No período, o indicador que apresentou melhor desempenho foi o de pessoas em domicílios com renda per capita inferior a meio salário mínimo (2010) e dependentes de idosos, cuja redução chegou a 46,14\%.

Acerca dos indicadores que compõem o IVS Infraestrutura Urbana, a Tabela 3 apresenta os dados dos anos de 2000 e 2010.

Tabela 3 - Índice de Vulnerabilidade Social: Dimensão Infraestrutura Urbana do município de São Miguel/RN (2000-2010)

\begin{tabular}{|c|c|c|c|}
\hline & \multicolumn{2}{|c|}{ ANO } & \multirow{2}{*}{$\begin{array}{c}\text { Variação } \\
\text { 2000-2010 } \\
-\end{array}$} \\
\hline & 2000 & 2010 & \\
\hline IVS Dimensão Infraestrutura Urbana & 0.624 & 0.437 & $-29,96 \%$ \\
\hline $\begin{array}{l}\% \text { de pessoas em domicílios com abastecimento de água e } \\
\text { esgotamento sanitário inadequados }\end{array}$ & 36,87 & 18,57 & $-49.63 \%$ \\
\hline $\begin{array}{l}\text { \% da população que vive em domicílios urbanos sem o serviço de } \\
\text { coleta de lixo }\end{array}$ & 14,95 & 4,58 & $-69 \%$ \\
\hline $\begin{array}{l}\% \text { de pessoas que vivem em domicílios com renda per capita } \\
\text { inferior a meio salário mínimo (de 2010) e que gastam mais de } \\
\text { uma hora até o trabalho }\end{array}$ & 2,65 & 2,65 & $0 \%$ \\
\hline
\end{tabular}

Fonte: IPEA (2000, 2010).

O IVS referente a dimensão Infraestrutura Urbana envolve aspectos que contribuem para a qualidade de vida da população, pois estão ligados diretamente ao lugar de domicílio. Em São Miguel/RN, o IVS Infraestrutura Urbana apresentou em 2000 um indicador de 0.624 , reduzindo para 0.437 em 2010, aspecto que deslocou o município da situação de muito alta para alta vulnerabilidade social, apresentando redução de 29,96\%, refletindo uma melhor distribuição e acesso aos serviços de saneamento básico e de mobilidade urbana.

A Tabela 3 apresenta o percentual de domicílios em que o abastecimento de água não é fornecido por uma rede geral e o esgotamento sanitário também não é realizado por nenhum órgão público responsável, em 2000, o percentual de domicílios foi de $36,87 \%$. Para a população que vive em domicílios urbanos sem o serviço de coleta de lixo, ou seja que não é recolhido pela gestão municipal o percentual de domicílios foi de 
14,95\%. Ainda de acordo com a Tabela 3, o percentual das pessoas que vivem em domicílios com renda per capita inferior a meio salário mínimo ( $\mathrm{R}$ 255,00 valor de referência de 2010) e que no deslocamento até o trabalho gastavam mais de uma hora até o trabalho correspondeu a 2,65\%.

Nota-se, em 2010, uma melhoria representativa no serviço de coleta de lixo realizado no município, com redução de aproximadamente $69 \%$. Em relação ao percentual de pessoas que vivem em domicílios com renda per capita inferior a meio salário mínimo (valor de referência de 2010) e que gastam mais de uma hora até o trabalho não houve alteração, permanecendo com 2,65\%.

A Tabela 4 traz os dados dos indicadores que compõem a dimensão Capital Humano, que compreende condições de saúde e acesso à educação.

Tabela 4 - Índice de Vulnerabilidade Social: Capital Humano do município de São Miguel/RN (2000-2010)

\begin{tabular}{l|c|c|c}
\hline \multicolumn{1}{c|}{ Tipos de ocorrências e variações } & \multicolumn{2}{c|}{ ANO } & Variação 2000- \\
\cline { 2 - 4 } & $\mathbf{2 0 0 0}$ & $\mathbf{2 0 1 0}$ & - \\
\hline IVS Capital Humano & $\mathbf{0 . 6 3 4}$ & $\mathbf{0 . 4 3 7}$ & $-31.07 \%$ \\
\hline Mortalidade até 1 ano de idade & 50,63 & 27,76 & $-45,17 \%$ \\
\hline \% de crianças de 0 a 5 anos que não frequentam a escola & 73,55 & 56,45 & $-23.24 \%$ \\
\hline \% de pessoas de 6 a 14 anos que não frequentam a escola & 3,98 & 3,41 & $-14.32 \%$ \\
\hline \% de mulheres de 10 a 17 anos que tiveram filhos & 1,70 & 2,32 & $\mathbf{+ 3 6 , 4 8 \%}$ \\
\hline $\begin{array}{l}\text { \% de mães chefes de família, sem Ensino Fundamental completo } \\
\text { e com filho menor de 15 anos de idade }\end{array}$ & 13,79 & 17,38 & $\mathbf{+ 2 6 , 0 4 \%}$ \\
\hline $\begin{array}{l}\text { Taxa de analfabetismo da população de 15 anos ou mais de } \\
\text { idade }\end{array}$ & 40,01 & 30,17 & $-\mathbf{2 4 , 5 9 \%}$ \\
\hline $\begin{array}{l}\text { \% de crianças que vivem em domicílios em que nenhum dos } \\
\text { moradores tem o Ensino Fundamental completo }\end{array}$ & 73,62 & 44,27 & $\mathbf{- 3 9 , 8 6 \%}$ \\
\hline $\begin{array}{l}\text { \% de pessoas de 15 a 24 anos que não estudam, não trabalham e } \\
\text { possuem renda domiciliar per capita igual ou inferior a meio } \\
\text { salário mínimo (valor de referência de 2010) }\end{array}$ & 22,87 & 22,36 & $-2.28 \%$ \\
\hline
\end{tabular}

Fonte: IPEA $(2000,2010)$.

A dimensão Capital Humano, conforme dados do IPEA (2000, 2010), obteve, em 2000, um indicador de 0.634 e 10 anos mais tarde ficou em 0.437, representando uma redução de $28.08 \%$. Conforme os dados da Tabela 4 , as variáveis que formam o IVS Capital Humano revelam que, entre 2000 e 2010, houve uma redução de 45,17\% no

Geopauta, Vitória da Conquista ISSN: 2594-5033, V. 5, n. 1, 2021, e7053

Este é um artigo de acesso aberto sob a licença Creative Commons da CC BY 

NASCIMENTO, T.B.C.; FILHO, B. de F.B.

percentual de crianças nascidas vivas que não sobreviveram ao primeiro ano de vida, mas ainda apresentando um indicador muito acima da média nacional $(16,7 \%$, conforme Quadro 1).

O percentual de mulheres de 10 a 17 anos que tiveram filhos, em 2000, foi de 1,70\%; a taxa de analfabetismo referente a população de 15 anos ou mais de idade que não sabe ler nem escrever foi de 40,01\%; as mães chefes de família, sem fundamental completo e com filho menor de 15 anos de idade chegou a 13,79\%; e para as pessoas de 15 a 24 anos que não estudam, não trabalham e possuem renda domiciliar per capita igual ou inferior a meio salário mínimo (valor de referência de 2010) foi de 22,87\%. Observa-se que o município reduziu, ainda que modestamente, o percentual das crianças de 0 a 5 anos que não frequentam a escola ou creche, com menos 23,24\%, e também das crianças de 6 a 14 anos que não frequentam a escola, com menos 14,32\%.

Nota-se um crescimento de $36,48 \%$ no percentual de mulheres de 10 a 17 anos que tiveram filhos e ainda um crescimento de 26,04\% das mães chefes de famílias, sem fundamental completo com filho menor de 15 anos de idade. Tais dados refletem um quadro preocupante de gravidez na adolescência, resultando em abandono precoce da escola por parte das mães e tendo que assumir a manutenção das famílias. O indicador referente ao percentual de pessoas de 15 a 24 anos que não estudam, não trabalham e possuem renda domiciliar per capita igual ou inferior a meio salário mínimo se manteve razoavelmente estável. A taxa de analfabetismo referente a população de 15 anos ou mais de idade e que não sabe ler nem escrever caiu $24,59 \%$. O percentual de crianças que vivem em domicílios em que nenhum dos moradores tem o Ensino Fundamental completo também reduziu 39,86\%.

A carta imagem 1 e o mapa 2, demonstram a evolução do IVS geral do município, permitindo uma melhor visualização e possibilidade de comparação com o entorno e demais municípios do Rio Grande do Norte. 
Carta imagem 1 - Índice de Vulnerabilidade Social dos municípios potiguares (2000) Destaque para São Miguel/RN

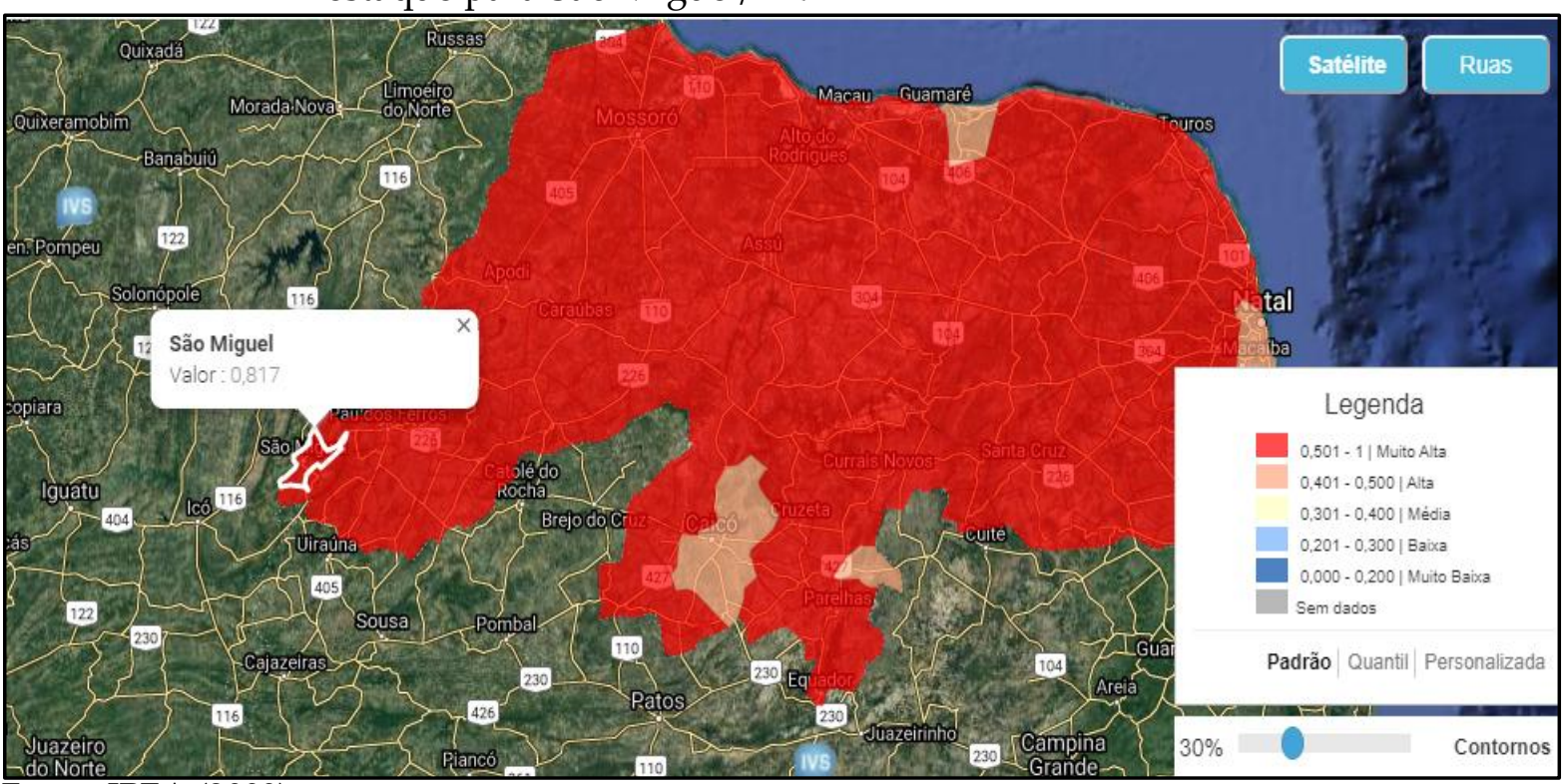

Fonte: IPEA (2000).

Verifica-se que em 2000 quase todos os municípios do RN apresentaram elevados índices de vulnerabilidade social, com nítida predominância de muito alta vulnerabilidade social, demonstrado uma imagem homogênea para todo o estado.

Mapa 2 - Índice de Vulnerabilidade Social dos municípios potiguares (2010) - Destaque para São Miguel/RN

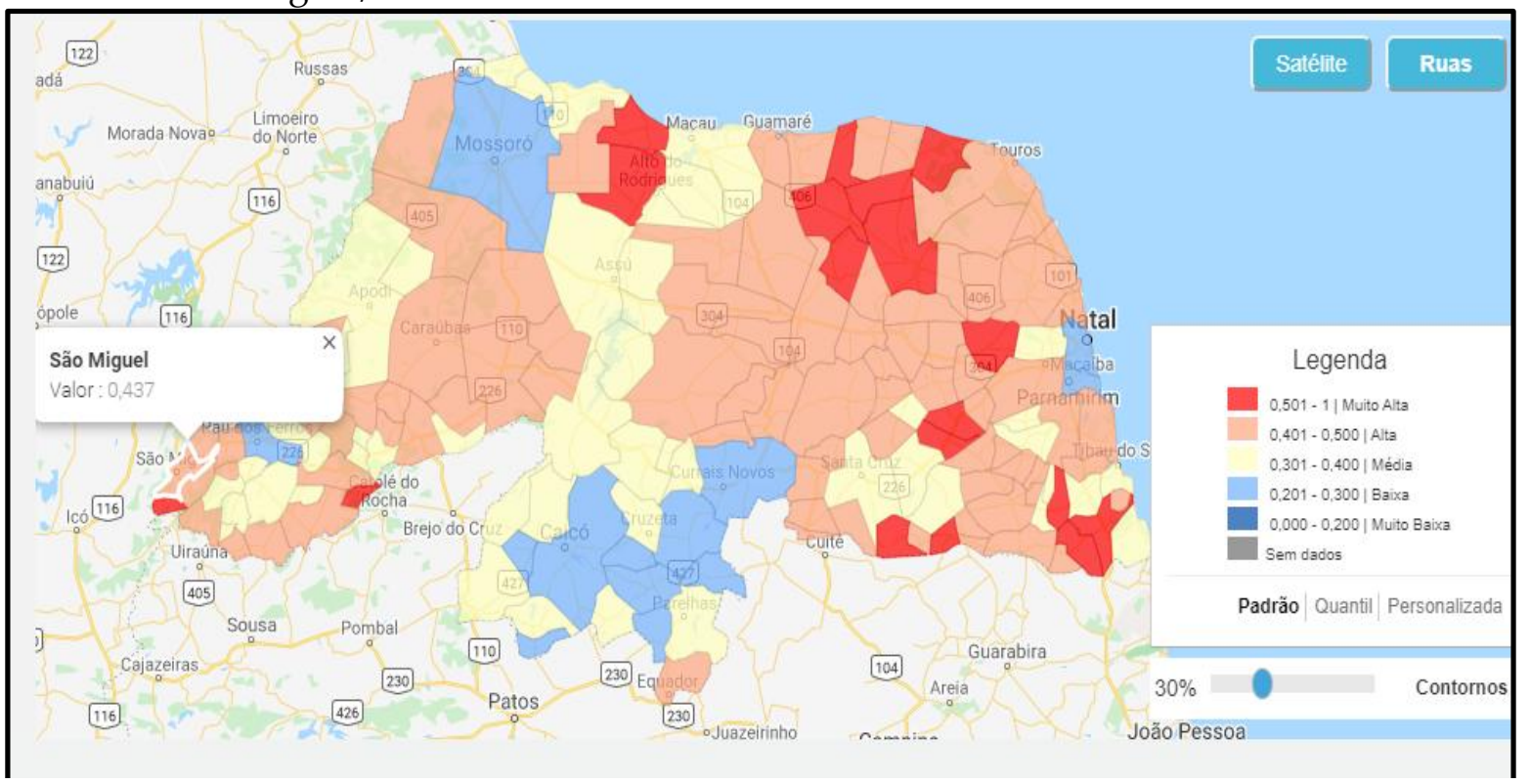

Fonte: IPEA (2010).

Geopauta, Vitória da Conquista ISSN: 2594-5033, V. 5, n. 1, 2021, e7053 
No decorrer de 10 anos, o cenário potiguar se modificou com significativa melhoria do indicador de vulnerabilidade social, contudo os avanços não ocorreram de forma homogênea em todo o território do estado. Conforme se observa na Figura 4, o RN passou a contar com a presença de diferentes faixas, reduzindo-se assim a predominância dos municípios na faixa da muito alta vulnerabilidade social. A melhoria também ocorreu no município de São Miguel/RN, mas ainda de forma moderada.

\section{Considerações finais}

O trabalho se propôs a analisar o desenvolvimento socioeconômico do município de São Miguel/RN, localizado no Alto Oeste Potiguar e seus determinantes de (20002010), por meio do IVS. Para os anos de 2000 a 2010 o IVS, passou da faixa de muito alta vulnerabilidade social para a situação de alta vulnerabilidade, colocando o município com a segunda maior redução da vulnerabilidade social na Microrregião da Serra de São Miguel, resultando num índice geral de 0.437. Tal desempenho indica que, apesar da evolução, melhorando a situação da faixa de vulnerabilidade, o município não se aproximou do índice nacional (0.326 em 2010).

O estudo do IVS Infraestrutura Urbana possibilitou a identificação da melhora significativa, com queda de 49,63\%, do percentual de domicílios com abastecimento de água e esgotamento sanitário inadequados e que não possuíam suas residências conectadas a redes de esgoto. Ainda nessa dimensão, verificou-se grande progresso da população que vivia em domicílios urbanos sem o serviço de coleta de lixo, cuja redução foi de aproximadamente $69 \%$ e, sem evolução nenhuma ficou o indicador do percentual de pessoas que vivem em domicílios com renda per capita inferior a meio salário mínimo (valor de referência de 2010) e que gastam mais de uma hora até o trabalho. 
Para o IVS Renda e Trabalho, o indicador com melhor desempenho foi o percentual de pessoas em domicílios com renda per capita inferior a meio salário mínimo (2010) e dependentes de idosos, que caiu 46,14\%, constatou-se ainda que nessa dimensão o indicador com menor evolução foi para o percentual de pessoas de 18 anos ou mais sem fundamental completo e em ocupação informal, com redução de $20 \%$.

O IVS Capital Humano apontou uma redução considerável de 45,17\% dos casos de mortalidade infantil. Esse resultado pode estar associado a melhoria das condições de vida no que se refere aos cuidados com pré-natal, funcionamento da Estratégia de Saúde da Família, campanhas de vacinação, programas que permitem melhor nutrição para as gestantes e crianças, e podendo ainda estarem associadas às melhorias nas condições de infraestrutura urbana. Para essa dimensão do IVS Capital Humano as mulheres de 10 a 17 anos que tiveram filhos elevou seu percentual em $36,48 \%$, essa piora se estendeu ainda para as mães chefes de família, sem fundamental completo e com filho menor de 15 anos de idade que aumentou 26,03\%, salientando as dificuldades do município de enfrentar essa problemática que é a falta educação sexual e a necessidade de mães chefes de família abandonar os estudos em virtude da difícil tarefa que é conciliar a vida cotidiana com a vida acadêmica, devendo-se ressaltar a importância de melhores níveis educacionais das mães para a educação das futuras gerações, sinalizando para as autoridades que medidas devem ser adotadas para assegurar a permanência das mães chefes de família na escola.

Os dados apresentados permitem a identificação de setores e aspectos que influenciam nas condições de vida da população, bem como os que merecem uma maior atenção por parte da gestão pública para a criação ou aperfeiçoamento de políticas públicas direcionadas para as áreas mais vulneráveis, assim, permanece a necessidade de estudos mais detalhados, aprofundando-se a compreensão de cada dimensão e dos diversos indicadores que compõem o quadro socioeconômico de São Miguel/RN. 
Saliente-se que a dimensão de Infraestrutura Urbana, além de ter contribuído com o maior percentual para a melhoria do IVS micaelense, com $46,69 \%$, contribui para a melhoria das condições de vida em diferentes aspectos, agregando melhor dotação de infraestrutura, podendo contribuir como fator potencializador para o desenvolvimento socioeconômico, considerando-se como um elemento que deve merecer atenção por parte do Poder Público.

\section{Referências}

AMARO, Rogério Roque. Desenvolvimento - um conceito ultrapassado ou em renovação? Da teoria à prática e da prática à teoria. Cadernos de estudos africanos, $\mathrm{n}$. 4, p. 35-70, 2003.

BARRETO FILHO, Boanerges de Freitas. Alto Oeste Potiguar (1700-2017): Estrutura econômica, dinâmica urbana e regionalização. 2018. 212 f. Dissertação de mestrado. Universidade do Estado do Rio Grande do Norte (UERN). Mestrado em Planejamento e Dinâmicas Territoriais no Semiárido. Pau dos Ferros/RN: UERN, 2018. Disponível em: $<$ https://sucupira.capes.gov.br/sucupira/public/consultas/coleta/trabalhoConclusao/vie wTrabalhoConclusao.jsf?popup=true\&id trabalho=6373239>. Acesso em: 10 jan. 2020.

BRESSER-PEREIRA, Luiz Carlos. Crescimento e desenvolvimento econômico. Notas para uso em curso de desenvolvimento econômico na Escola de Economia de São Paulo da Fundação Getúlio Vargas. Versão de junho de 2008.

BRESSER-PEREIRA, Luiz Carlos. O conceito histórico de desenvolvimento econômico. Texto para Discussão no ${ }^{157}$. Escola de Economia de São Paulo da Fundação Getulio Vargas FGV-EESP, 2006.

CAMARGO, José Osvaldo Leite. Proposição de um modelo de diagnóstico socioeconômico municipal. Trabalho de Conclusão de Curso - Departamento de Ciências Administrativas, Contábeis, Econômicas e da Comunicação (DACEC), Ijuí/RS, 2015.

INSTITUTO BRASILEIRO DE GEOGRAFIA E ESTATÍSTICA (IBGE). Histórico. São Miguel/RN. Disponível em: <https://cidades.ibge.gov.br/brasil/rn/sao-miguel/historico>. Acesso em: 10 jan. 2020.

INSTITUTO BRASILEIRO DE GEOGRAFIA E ESTATÍSTICA (IBGE). Panorama. 2017. Disponível em: <http://www. ibge.gov.br/cidades>. Acesso em: 25 set. 2019. 
INSTITUTO BRASILEIRO DE GEOGRAFIA E ESTATÍSTICA (IBGE). Censo

Demográfico de 2010. Disponível em: $<$ http://www. ibge.gov.br/cidades $>$. Acesso em: 20 set. 2019.

INSTITUTO BRASILEIRO DE GEOGRAFIA E ESTATÍSTICA (IBGE). Censo

Demográfico de 2000. Disponível em: $<$ http://www. ibge.gov.br/cidades $>$. Acesso em: 20 set. 2019.

CORRÊA, Vanessa Petrelli. Desenvolvimento Territorial e a Implantação de Políticas Públicas Brasileiras Vinculadas a esta Perspectiva. Boletim Regional, Urbano e Ambiental (BRU): n. 3, dez. 2009. 2009.

COSTA, Marco Aurélio; MARGUTI, Bárbara Oliveira; PIRANI, Nikolas de Camargo. O Território em índices: a experiência do Ipea na construção do Índice de Vulnerabilidade Social (IVS) e a possibilidade de novos olhares sobre diferentes escalas do território, 2016.

DUBIEL, Sonise Aparecida; RAIHER, Augusta Pelinski. Desenvolvimento econômico dos municípios do Paraná: evolução e seus determinantes. Informe Gepec, v. 17, n. 2, p. 6-22, 2013.

FUNDAÇÃO CEPRO. O Índice de Vulnerabilidade Social no Piauí por Territórios de Desenvolvimento. Teresina/PI: Fundação CEPRO, 2018.

FURTADO, Celso. Teoria e política do desenvolvimento econômico. $2^{\underline{a}}$ edição, Editora Nacional. São Paulo, 1968.

GIL, Antônio Carlos. Como Elaborar Projeto de Pesquisa. 5.ed. São Paulo, 2010.

INSTITUTO DE PESQUISA ECONÔMICA APLICADA (São Paulo). Instituto Geográfico e Cartográfico. Brasil em Desenvolvimento: Estado, planejamento e políticas: (Brasil: o estado de uma nação). 3. ed. São Paulo: Njobs Comunicação, 2009.

JANNUZZI, Paulo de Martino. Indicadores Sociais na Formulação e Avaliação de Políticas Públicas, 2002.

JANNUZZI, Paulo de Martino. Indicadores Sociais no Brasil: Conceitos. Fontes de Dados, 2001.

LAMPREIA, Luiz Felipe. Relatório brasileiro sobre desenvolvimento social. Estudos Avançados, v. 9, n. 24, p. 9-74, 1995.

OLIVEIRA, Gilson Batista de. Uma discussão sobre o conceito de desenvolvimento. Revista da FAE, v. 5, n. 2, 2002.

PIRES, Elson Luciano S. Território, governança e desenvolvimento: questões fundamentais. Caderno Prudentino de Geografia, v. 2, n. 38, p. 24-49, 2016. 
RODRIGUES, Waldecy; SANTOS, Nayara Silva. Territorial development in Brazil: an analysis from Karl Polanyi. Interações (Campo Grande), v. 19, n. 1, p. 119-135, 2018.

SACHS, Ignacy. O desenvolvimento enquanto apropriação dos direitos humanos. Estudos avançados, v. 12, n. 33, p. 149-156, 1998.

SACHS, Ignacy. Caminhos para o desenvolvimento sustentável. Rio de Janeiro: Editora Garamond, 2002.

SIEDENBERG, Dieter Rugard. Indicadores de desenvolvimento socioeconômico: uma síntese. Desenvolvimento em Questão, v. 1, n. 1, p. 45-71, 2003.

SILVA, Sandro Pereira. A abordagem Territorial no Planejamento de Políticas Públicas e os Desafios para uma Nova Relação entre Estado e Sociedade no Brasil. In: BOUERI, Rogério; COSTA, Marco Aurélio. Brasil em desenvolvimento 2013: estado, planejamento e políticas públicas. Brasília/DF: IPEA, 2013. Disponível em: <http://repositorio.ipea.gov.br/bitstream/11058/3911/1/LivroBrasil em desenvolvimento 2013 v 1.pdf $>$. Acesso em: 10 jan. 2020.

SILVA, Samwel Sennen D.'awyla Bezerra; BEZERRA, Josué Alencar. A expansão urbana de São Miguel (RN): planejamento urbano e conformidades em uma cidade de pequeno porte. Acta Geográfica, v. 12, n. 30, p. 131-149, 2019.

VASCONCELOS, Marco Antonio; GARCIA, Manuel Enriquez. Fundamentos de economia. São Paulo: Saraiva, 1998.

VEIGA, José Eli da. Desenvolvimento sustentável: o desafio do século XXI. Rio de Janeiro: Garamond, 2005.

Contribuição dos autores:

Thaísa Bruna Costa Nascimento; Elaboração, discussão dos resultados, pesquisa bibliográfica, revisão do texto Boanerges de Freitas Barreto Filho: Supervisão, análise final dos resultados e revisão do texto 